\title{
The EEC syndrome and its ocular manifestations
}

\author{
ALAN A McNAB,* MICHAEL J POTTS, ANd RICHARD A N WELHAM \\ From the Lacrimal Clinic, Moorfields Eye Hospital, London, EC1V 2PD
}

SUMMARY The EEC syndrome (ectrodactyly or lobster-claw deformity, ectodermal dysplasia, and cleft lip and palate) is a rare disorder with autosomal dominant inheritance, variable expression, and in some families lack of penetrance. We present the findings in five cases with emphasis on the ocular findings. Lacrimal surgery was performed on three patients with good results in each case. We also report the occurrence of spontaneous corneal perforation in two cases, a complication not previously recognised. The ophthalmic care of these patients must be pursued long-term, as progressive visual impairment may be the most disabling feature of the syndrome.

The EEC syndrome, and acronym coined by Rudiger et al in 1970, ${ }^{1}$ was first recognised as a distinct clinical entity by Cockayne. ${ }^{2} \mathrm{He}$ drew attention to the dacryocystitis which commonly afflicts these patients, and found that it was associated with 'atresia of the lacrimal ducts.' Since that description in 1936, several other reports have appeared in the ophthalmic literature ${ }^{3-6}$ detailing the ocular findings in the syndrome. Five cases in three families have presented to the Lacrimal Clinic at Moorfields Eye Hospital between 1981 and 1987 and three have undergone lacrimal surgery.

We present the clinical details of each of these five patients, three of whom are from one family, a mother and two daughters.

\section{Case reports}

\section{CASE 1}

This girl is an older sister of case 2 and the daughter of case 3 . She is the third of four children, an older brother and sister being unaffected. Her parents are unrelated and of Sikh Indian origin.

Both eyes had watered from birth, with intermittent mucopurulent discharge. She had been born after a normal pregnancy with bilateral cleft lip and palate which were surgically repaired at the age of 6 months. Her right hand showed ectrodactyly and a surgical procedure was performed at 6 years to

Correspondence to Mr R A N Welham, Moorfields Eye Hospital, City Road, London EC1V 2PD.

* Supported by the Royal Australian College of OphthalmologistsOPSM Travelling Fellowship. provide a more functional hand. Both feet had syndactyly. Her hair was coarse and dry and her skin subject to eczema. She had a bilateral conductive hearing loss and wore hearing aids. There was bilateral malar hypoplasia and small malformed teeth.

We first saw her at the age of 11 years. Visual acuity was $6 / 6$ right and $6 / 5$ left. Her lids were thickened by an eczematoid skin change and were cracked and scaling. There was a moderate watery discharge from each eye. All four lacrimal puncta were occluded by a thin membrane, but their positions were normal and easily discernible. Slit-lamp examination was hampered by severe photophobia, but both corneas appeared normal, and the irides were brown without any transillumination defects. The rest of the ocular examination gave normal findings.

Each lacrimal system was explored under general anaesthesia on separate occasions, and the findings were similar. The thin membranes occluding the puncta were easily perforated by a punctum dilator, but there was no true ampulla. Probes passed easily into the lacrimal sac, but the lid margins medial to the puncta were thinned, with the probes seen easily through the overlying epithelium. When exposed, the lacrimal sac was found to be grossly enlarged, thin walled, and filled with mucus. There was no membranous or bony nasolacrimal duct. A formal dacryocystorhinostomy (DCR) was performed on each side with intubation of the canaliculi. The tubes cheese wired through the lid margins for 2-3 mm and were removed after one month. The patient is free of epiphora. 
CASE 2

This girl is the youngest of four children and the sister of case 1 . She was brought to the Lacrimal Clinic at the age of $31 / 2$ years with a history of bilateral epiphora from birth. She had been born after a normal pregnancy with bilateral cleft lip and palate. There was ectrodactyly of both hands and the left foot, with mild syndactyly of the right foot. At nine months the cleft lip and palate were repaired, and at $41 \frac{1}{2}$ years the more severely affected left hand was modified to provide a more functional grip.

The child's skin was noticeably fairer than her parents' and her hair was coarse and dry, with patchy alopecia. There was malar and mandibular hypoplasia, but her first dentition appeared normal other than being carious. She wore a hearing aid on the right for a conductive hearing loss.

The right lacrimal system had been probed and intubated at another hospital at nine months, and the tube remained in situ for three weeks. Watering persisted after its removal. When she was first seen in the Lacrimal Clinic aged $3 \frac{1}{2}$ visual acuities were normal. The right upper and lower puncta appeared slit-like. The left puncta and lids were normal. There were bilateral mucocoeles. The rest of the ocular examination gave normal results.

Right and then left DCRs were performed three months apart. On the right there was a large mucocoele, with an obstructed nasolacrimal duct. The bony nasolacrimal canal was, however, present. On the left the lacrimal sac was again dilated, but there was no membranous or bony nasolacrimal canal. Both DCRs were successful, and the child is free of watering.

\section{CASE 3}

The mother of the two girls above (cases 1 and 2) had only mild features of the syndrome. Her left hand showed polydactyly with a rudimentary digit attached to the radial side of the thumb and syndactyly of both feet. There was no lip or palate abnormality, and ocular examination gave normal findings apart from some trichiasis of the medial third of each lower lid and slight retroplacement of the lower puncta behind the lid margin. Skin, hair, and teeth were of normal appearance. There were no further affected family members.

\section{CASE 4}

This boy was first seen by us at the age of 13 with a spontaneous corneal perforation. He had been born with multiple abnormalities including a left sided cleft lip and palate, ectrodactyly of both hands, and syndactyly of the right foot. He had required bilateral reimplantation of the ureters for vesicoureteric reflux. His skin had always been dry. There had been recurrent bouts of sticky discharge from both eyes since birth, but there was no watering between these episodes. The only positive family history was a 'crippled' maternal grandfather, but no details were available. His parents and one sibling, a brother, are unaffected.

Two months before presentation to Moorfields he had again developed a discharge from the left eye. This was treated with topical gentamicin, tetracycline, and weak steroid drops, but the symptoms were slow to resolve. On the day before admission he felt a sudden 'flash' in the eye followed by watering and blurred vision. Visual acuity was $6 / 4$ right and 6/36 left. The left cornea had an area of central thinning, with a small perforation below the visual axis and a shallowed anterior chamber. The perforation was sealed by a knuckle of iris (Fig 1). Both corneas also showed old peripheral stromal infiltrates and scars. He had normal brown irides. The lids showed mild blepharitis. Both upper puncta were absent as was the right lower punctum. The left lower puntum was normal, but there was a lacrimal fistula opening on to the skin several millimetres below the medial canthus, and pus was easily expressible from it on massaging the lacrimal sac.

The corneal perforation was managed conservatively with the fitting of a soft silicone lens. The anterior chamber reformed, and the perforation healed. Vision recovered to $6 / 9$, and the cornea was left with a small stromal scar just below the visual axis and some peripheral superficial stromal vascularisation and infiltrates.

A dacryocystogram was performed and showed a

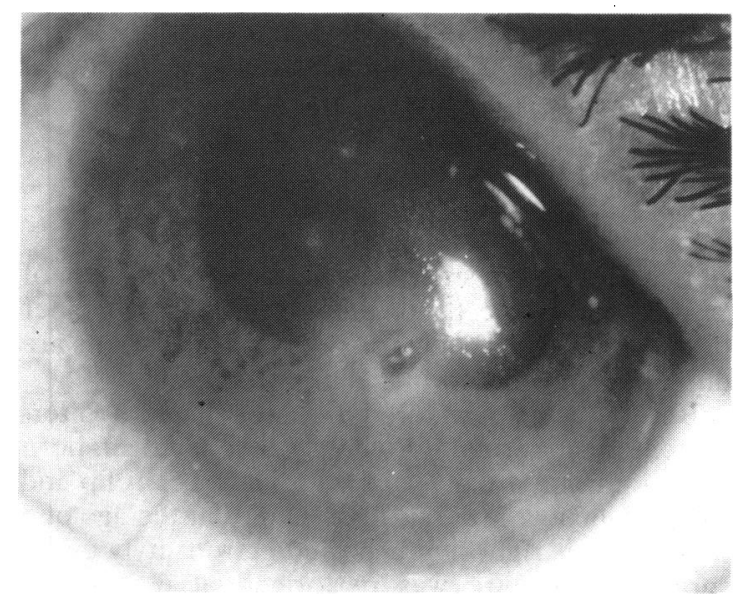

Fig. 1 Case 4. Spontaneous perforation of the left cornea. There is an area of central thinning and a small perforation plugged by iris. A soft silicon contact lens is in situ. Vision recovered to $6 / 9$. 
mucocoele with a diverticulum. Five months later the left lacrimal system was surgically explored. The fistula originated from the common canaliculus (the commonest site for the origin of congenital fistulas'). It was excised and a formal DCR completed. No upper canaliculus was found, and there was no bony nasolacrimal canal. The patient has been free of discharge up to five years later. It was decided not to operate on the right lacrimal system as there was no watering and no evidence of a mucocoele.

\section{CASE 5}

We first saw this young woman at the age of 23 . She had been born with ectrodactyly of all four extremities (Figs 2 and 3 ) and ectodermal dysplasia manifest as dry skin and coarse dry hair. She had required multiple dental procedures for partial anodontia and hypodontia. Her father suffered from the same condition, but there was no other positive family history, her two siblings being unaffected. Unfortunately the father refused to be examined, but he was reported as having the same skin, hair, dental, and limb anomalies. Neither he nor his daughter had abnormalities of the lip or palate.

Both eyes watered from birth, and she had an unsuccessful right DCR in childhood. In more recent years she felt her eyes were dry, and she had used artificial tears with some relief. At the age of 21 her right cornea had spontaneously perforated without any antecedent history of infection. It had healed with the aid of a soft contact lens, and no surgery was required. Early in 1987 she had developed acute right dacryocystitis requiring systemic antibiotics.

When seen by us in December 1987 the vision was $6 / 18$ in the previously perforated right eye and $6 / 12$ in the left. There was trichiasis of the medial third of the lower eyelids. The right upper punctum was absent and the lower was occluded by a thin membrane with only $2 \mathrm{~mm}$ of canaliculus on probing beyond this. There was no clinical evidence of the mucocoele and

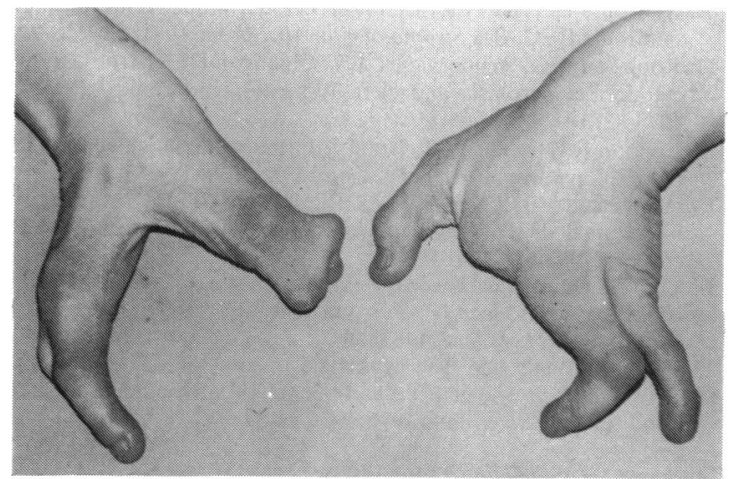

Fig. 2 Case 5. Severe ectrodactyly of both hands. no patency on attempted syringing through the lower punctum. The puncta and canaliculi were normal on the left with patency to syringing. There was a poor tear film on each side. The right cornea showed extensive superficial stromal vascularisation with central thinning. On the left there was some pannus superiorly. The remainder of the ocular examination was normal. The irides were blue and the hair pale brown.

It was elected not to perform lacrimal drainage surgery on the right unless she developed a further attack of dacryocystitis.

\section{Discussion}

From the five cases presented it is apparent that the EEC syndrome has a variable expression. In naming this the EEC syndrome, Rudiger et al. ${ }^{1}$ drew attention to the three features of the condition, namely ectrodactyly, ectodermal dysplasia, and cleft lip and palate. Dacryocystitis secondary to congenital lacrimal duct anomalies was noted by Cockayne in the first published report of the syndrome. ${ }^{2}$ Other patients reported in the ophthalmic and general literature ${ }^{3.68 .10}$ have had varying combinations of blepharitis, conjunctivitis, corneal scarring, and pannus with photophobia, and poor lacrimal and meibomian secretion. Blue irides and albinoid features are said to be common, as is entropion with trichiasis and in some cases madarosis. Most of these affected structures are ectodermally derived, and it is not surprising to see such features in a condition with widespread ectodermal dysplasia manifest elsewhere as skin, hair, nail, and teeth changes. The lacrimal drainage apparatus is also derived from surface ectoderm and commonly affected. Despite its ectodermal origin, the crystalline lens has not been found to be abnormal.

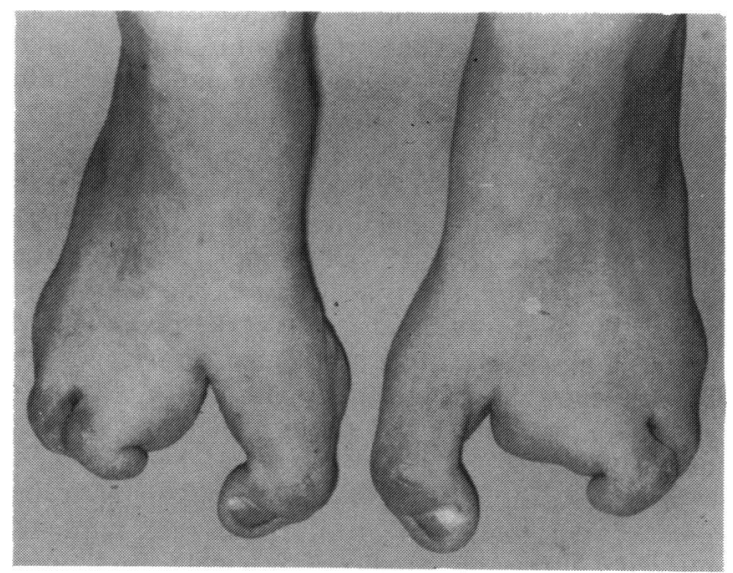

Fig. 3 Case 5. Ectrodactyly of the feet. 
That two of our patients developed spontaneous corneal perforations seems to be more than coincidence There are many reasons for patients such as these to develop such a complication: the cornea is partially derived from ectoderm, there are tear film and lid abnormalities, there may be trichiasis and an obstructed lacrimal drainage apparatus harbouring potentially pathogenic organisms. One of our patients had been on weak steroid drops, and this may have contributed to the development of the perforation. To the best of our knowledge, however, these are the first reports of this complication in the EEC syndrome. Both responded to conservative treatment with bandage lenses, and good visual acuity was preserved.

The EEC syndrome has been found in association with conductive hearing loss. ${ }^{11}$ Our first two cases both had hearing defects. Robinson et al. ${ }^{11}$ found a congenital absence of the stapes and part of the incus in one of three members of a family whose affected members had a conductive hearing loss in addition to the other features of the syndrome. Urinary tract anomalies as exemplified by case 4 have also been observed by others, ${ }^{12}$ and the letters UT (urinary tract) have been appended to EEC to describe the syndrome in such individuals. Rare cases of ectrodactyly and ectodermal dysplasia have also been seen in association with a retinal macular dystrophy and dubbed the EEM syndrome. ${ }^{13{ }^{14}}$ In addition a syndrome of ankyloblepharon, ectodermal defects, and cleft lip and palate (the AEC syndrome) has been described in association with lacrimal duct atresia. ${ }^{15}$

The autosomal dominant inheritance in some families of atresia of the lacrimal canaliculi is well known. Obstruction of the nasolacrimal duct in association with cleft lip and palate is often observed. We have also seen a family with ectodermal dysplasia whose affected members had absent lacrimal puncta. However, in our experience the patients with the EEC syndrome form the largest group, showing an association between limb deformities and lacrimal drainage anomalies. These anomalies are quite variable, however, and are not unique to the EEC syndrome.

Cleft lip and palate are usually repaired early in life, and the patients appear to adapt well to the limb deformities of the EEC syndrome. However, the ocular complications may be progressive and threaten sight. It is therefore important that these patients be under long-term ophthalmic supervision to try to prevent the sight threatening corneal complications and to treat a corneal perforation which threatens the whole eye.

Lacrimal drainage surgery also forms an important part of the management of these rare patients. Obstructed lacrimal canaliculi or nasolacrimal ducts are not in themselves indications for surgery. Tearing seems often to be absent in these patients despite the obstructed outlet and is probably secondary to lacrimal gland dysfunction. In a patient with a dry eye and obstructed nasolacrimal ducts with mucocoele formation and sticky discharge, or frank dacryocystitis, surgery may be required. We operated successfully on three cases and experienced no particular technical difficulties. The only complication was cheese-wiring of the lid margins from the tubes inserted in case 1 . This was abetted by the abnormally thin lid margins overlying the canaliculi in this child. We have not found it necessary to resort to dacryocystectomy or Lester Jones bypass tubes as reported in some cases. ${ }^{45}$

We thank Mr Roger Buckley for allowing us to include his case, and all the other ophthalmologists who continue to support the Lacrimal Clinic at Moorfields by referring their patients.

\section{References}

1 Rudiger RA, Haase W, Passage E. Association of ectrodactyly, ectodermal dysplasia and cleft lip-palate. Am J Dis Child 1970; 120: $160-3$.

2 Cockayne EA. Cleft palate, hare lip, dacryocystitis and cleft hand and feet. Biometrika 1936; 28: 60-3.

3 Levy WJ. Mesoectodermal dysplasia, a new combination of anomalies. Am J Ophthalmol 1967; 63: 978-82.

4 Weigmann OA, Walker FA. The syndrome of lobster claw deformity and naso-lacrimal duct obstruction. $J$ Pediatr Ophthalmol Strabismus 1970; 7: 79-85.

5 Kaiser-Kupfer M. Ectrodactyly, ectodermal dysplasia and clefting syndrome. Am J Ophthalmol 1973; 76: 992-8.

6 Gualandri V, Ronzoni MG, Montagnini A, Orsini GB. Une famille atteinte de EEC-syndrome: variabilité clinique et conseil génétique. J Fr Ophthalmol 1986; 9: 855-7.

7 Bergin D, Welham RAN. Congenital lacrimal fistulas. Arch Ophthalmol 1985; 103: 545-8.

8 Walker JC, Clodius L. The syndrome of cleft lip, cleft palate and lobster claw deformities of the hands and feet. Plast Reconstr Surg 1963; 32: 627-36.

9 Bixler D, Spivach J, Bennett J, Christian JC. The ectrodactylyectodermal dysplasia-clefting (EEC) syndrome. Clin Genet 1971; 3: 43-51.

10 Psaume J, Gray F, Cousteau C, Trigo G. Douze observations du syndrome ectrodactylie, dysplasie ectodermique, fente faciale, syndrome EEC. Rev Stromatol Chir Maxillofac 1981; 82: 226-9.

11 Robinson GC, Wildervanck LS, Chiang DDS. Ectrodactyly, ectodermal dysplasia and cleft lip-palate syndrome. $J$ Pediatr 1973;82: 107-9.

12 London R, Heredia RM, Israel J. Urinary tract involvement in the EEC syndrome. Am J Dis Child 1985; 139: 1191-3.

13 Albrectsen B, Svendsen IB. Hypotrichosis, syndactyly and retinal degeneration in two siblings. Acta Derm Venereol (Stockh) 1956; 1: 96-101.

14 Ohdo S, Hirayama K, Terawaki T. Association of ectodermal dysplasia, ectrodactyly and macular dystrophy: the EEM syndrome. J Med Genet 1983; 20: 52-7.

15 Hay RJ, Wells RS. The syndrome of ankyloblepharon, ectodermal defects and cleft lip and palate: an autosomal dominant condition. Br J Dermatol 1976; 94: 277-89.

Accepted for publication 23 June 1988. 